\title{
A new Physics to support the Copernican system. Gleanings from Galileo's works
}

\author{
Giulio Peruzzi
}

Department of Physics, University of Padua, Italy email: peruzzi@pd.infn.it

\begin{abstract}
Galileo's support to the Copernican theory was decisive for the revolutionary astronomical discoveries he achieved in 1610. We trace the origins of Galileo's conversion to the Copernican theory, discussing in particular the Dialogo de Cecco di Ronchitti da Bruzene in perpuosito de La Stella Nuova. Later developments of Galileo's works are briefly treated.
\end{abstract}

Keywords. History of Science, History of Astronomy, Galileo Galilei, Copernican System, Scientific Revolution.

\section{Introduction}

The use of the telescope alone doesn't explain the revolutionary astronomical discoveries achieved by Galileo from the end of 1609 onwards. To look doesn't mean to see, and the "sensate esperienze" must integrate observation and experimentation. Galileo looks and sees because in preceding years he had freed himself from prevailing convictions and he had progressively become aware that the facts he was studying both in the Heavens and on the Earth went in the direction of confirming the Copernican system.

It is well known that one of the first evidences of his adherence to Copernicanism lies in a letter to Kepler written on $4^{\text {th }}$ August 1597 (Opere, vol. X, pp. 67-8, p. 68). Galileo is however well aware that the Copernican system, unlike the Aristotelian-Ptolemaic system, lacks a physics of its own. It is not by chance that in the years preceding the use of the telescope, his researches were devoted to both astronomy and the study of local motions. In this sense, it is emblematic that Galileo analyses the Stella Nova in the same year when he communicates to Sarpi his discovery of the law of falling bodies (letter on $16^{\text {th }}$ October 1604, Opere, vol. X, pp. 115-6, p. 115).

\section{The appearance of the Stella Nova}

October 1604. The astronomers are fixing their eyes towards the region of the sky between the constellation of Sagittarius and that of the Ophiuchus or Serpentarius. They are observing quite a rare event, though cyclically recurrent and foreseeable: the celestial conjunction of three planets, Jupiter, Saturn and Mars. Many people are thus scrutinizing that part of the Heavens when, with great amazement, they suddenly see - some say on 9 th and others on $10^{t h}$ October - a new source of light. The brightness of the new source of light increases during a couple of weeks and becomes equal to Venus. It then progressively decreases and finally disappears about one year and a half after its appearance.

Different kinds of emotions shake those who observe the phenomenon: a mixture of astonishment and fear, of superstition and curiosity emerges from letters and reports of that time. People recall a similar appearance and disappearance of a "stella nova" in 
the constellation of Cassiopeia, observed in November 1572 by Tycho Brahe, which had raised some clamour also within the population.

What was going on? We know a lot today about these appearances. We can observe their remnants with our sophisticated instruments and we have at our disposal quite a satisfying theory of the stellar evolution, which enables us to catalog the appearance of these celestial bodies within the great class of Variable Stars. It is thus sure that the phenomena observed in 1572 and 1604 were Supernovae (the term was introduced by Fritz Zwicky and Walter Baade in 1934), catastrophic events within the stellar evolution during which the brightness of a star suddenly increases so that the star becomes visible from great distances.

In 1604, however, the knowledge was much different. The prevailing conception, supported by Aristotle's followers, sharply separated celestial phenomena and objects from terrestrial ones. Celestial bodies, created $a b$ inizio by God, were made of a special substance, a highly perfect quintessence that did not undergo through any change; their perfection was mirrored by the perfection of their eternal circular motions. On the contrary, the sublunar region, including the atmosphere and the Earth, was the scene of changes, of life and death, of generation and corruption, and it hosted bodies made of the mixture of the four elements (earth, water, air and fire). These bodies, according to the proportion of their constituting elements, had their "natural" place at a given height or distance from the centre of the Earth: if they were in a different position, they moved (a "natural" motion) along a straight line, to go back to their natural place. The downwards motion of heavy bodies (towards the Earth's surface) and the upwards motion of flames were explained on the basis of this theory.

Such a conception of the Universe, imbued with theological and metaphysical elements, could not fit with the appearance of new stars: these appearances or generations had to be linked to entities or bodies located not in the celestial region but in the sublunar one, they had to be meteorological phenomena, though rare and strange. This is why the discussion on the new star focused on the position of the latter. The question did not involve only the explanation of an event, though such a peculiar one, but a millenarian conception of the Heavens based on a philosophy of nature that had become throughout the centuries more and more focused on the manipulation of bibliographies, the commenting of books and the research of an hypothetical consistency with the Holy Scriptures, forgetting little by little the importance of direct observation. A philosophy/theology of nature which tried to defend itself against attacks that, from the mid $16^{\text {th }}$ century, had been more and more frequent. The scientific controversy thus involved consolidated powers and authorities both in the Church and in the academic community.

In Padua, where the nova was observed for the first time on $10^{\text {th }}$ October, the controversy was very lively and involved the whole town, exciting curiosity and fears among the population and raising careful interest among scholars. Galileo, who was at the time professor of mathematics and astronomy at the University of Padua, particularly appreciated for his teaching capacities, had chosen "le teoriche dei pianeti" as the subject of his lessons for the year 1604-1605. It was thus natural that his friends and colleagues urged him to present his opinion about the phenomenon. He did so on three public lessons, which were probably held from the end of November and the first half of December 1604. The curiosity was such that more than thousand persons attended the lessons.

Unfortunately only some notes and a few fragments of the written texts of these lessons still survive in the archives (assuming that Galileo really completely wrote down his lessons). 
Anyway, their main aim seems clear. As Galileo writes, though everybody was interested in knowing about "de substantia, motu, loco et ratione apparitionis illius", he only wanted at that time "de motu et loco demonstrative constet" (Opere, vol. II, p. 278). From other sources, it is known for sure that Galileo intended to write down and publish his lessons. This is quite clear in a letter written by Alessandro Sertini to Galileo on $16^{\text {th }}$ April 1605 (Opere, vol. X, pp. 142-3, p. 143), and in an unfinished letter written in January 1605 by Galileo to an anonymous correspondent (maybe Onofrio Castelli or, more probably, Girolamo Mercuriale) (Opere, vol. X, pp. 134-5). In the latter, Galileo mentions reiterated requests to send "copia delle tre letioni fatte da me in pubblico" (Opere, vol. X, p. 134), and he says that the publication has already been repeatedly postponed and it is to be postponed again for a few more days, because the lessons have mainly dealt with the fact that the new star is much above the lunar orbit, while Galileo would now like to "mutarle in discorso et aggiugnervi circa la sustanza et generazione" (Opere, vol. X, p. 135) of the new star. Demonstrating that the star is much beyond the lunar orbit, Galileo writes, is quite "facile, manifesta e comune [...]; bisognò che io ne trattassi in grazia de i giovani scolari et della moltitudine bisognosa di intendere le demostrazioni geometriche" (Opere, vol. X, p. 134). But discussing the substance and generation of the nova was a much different matter. Galileo, in his letter, doesn't explicitly present his hypothesis on the subject (the autograph suddenly stops right with the sentence announcing a short summary of his ideas), he only explains that this hypothesis doesn't have evident contradictions and could thus be true, but he needs time to confirm it with observations, waiting for "il ritorno di essa stella in oriente dopo la separazione del sole, et di nuovo osservare con gran diligenza quali mutationi abbia fatto sì nel sito come nella visibile grandezza et qualità di lume $[. .$.$] . Et perché questa mia fantasia si tira dietro, o più tosto si mette avanti,$ grandissime conseguenze et conclusioni però ho risoluto di mutar le letioni in una parte di discorso" $\dagger$.

What was this "fantasia" rich in consequences Galileo was working on? First of all, though he did not take a definitive position about the nature of the nova (as he lacked indisputable evidences), Galileo started supporting, in those years, several hypothesis about the generation of the new star - that we will discuss later - that cancelled the difference between terrestrial and celestial physics. At the same time, Galileo hoped he could observe - but he did not succeed in this - the relative parallax of the Stella nova when the Earth was at opposite positions along its revolution orbit around the Sun, as he thought that the changing brightness of the nova was due to different distances from the Earth. This would have been a definitive proof that the Copernican system was true, against both the Ptolemaic system and the hybrid system proposed by Tycho Brahe. It is important to point out that in those very months, Galileo was working hard to study local motions, also in order to answer several objections to the Copernican system (an example: if the Earth is moving, why do we observe that a body falling from a tower arrives right at the base of the tower and not at a certain distance from it?). We can thus understand Galileo's emphasis about the consequences of his "fantasia".

$\dagger$ "the coming back of this star at east after the separation of the Sun, and observe again with great care what changes it [the star] shows both as for the position and the visible dimension and quality of light $[\ldots]$. And as this fantasia of mine brings extremely important consequences and conclusions forth, I have decided to turn the lessons into a part of a discorso" (Opere, vol. X, p. 135). 


\section{Il dialogo di Cecco Rochitti}

In Galileo's private correspondence, there are several letters from friends and acquaintances who sympathize with the antiaristotelian ideas which surely inspired the three public lessons held by Galileo. The Franciscan monk Ilario Altobelli, for instance, writes to Galileo on 3rd November 1604 (Opere, vol. X, pp 116-7), that "questo nuovo mostro del cielo" (Opere, vol. X, p. 117) seems to be there on purpose in order to "far impazzire i Peripatetici, ch'hanno creduto sin hora tante bugie in quella stella nova e miracolosa del 1572 , priva di moto e di parallasse" (Opere, vol. X, p. 117). And Altobelli insisted on this point in a letter to Galileo written on 25th November 1604 (Opere, vol. X, pp. 118-20), where he repeated that the new star was clearly located on the fixed stars sphere and that "il suo sito rende possibile ogni impossibilità conietturata di Aristotile, distrugendo ogni sua imaginatione" (Opere, vol. X, p. 118), in spite the "pertinacia" ("obstinacy") of "Peripatetici, o, per dir meglio, semifilosofi" ("Peripatetics or, to say it better, semiphilophers"), unable to confront the observation data (Opere, vol. X, p. 118). And Galileo, who carried out by himself observations and measures on the position and features of the new star, though probably not in a systematic way, acquired through this intense correspondence, further precious details not only on the 1604 stella nova but also on the previous appearances, in particular on the 1572 one, which he was studying by reading (and commenting) Tycho Brahe's works.

The antiaristotelian spirit of the three Galilean lessons raised a lively discussion in the Academic world, where scientific questions were mingled - as often they are - with personal, prestige and power questions. Cesare Cremonini in particular, authoritative scholar of Aristotle and holder of the first chair of Natural Philosophy at the University of Padua, openly criticised Galileo and supported the Aristotelian tradition. It is likely that Cremonini himself inspired, at least partially, the publication in Padua, at the end of January 1605, of the Discorso intorno alla nuova stella by Antonio Lorenzini da Montepulciano. The core of Lorenzini's argumentation was the strenuous defense of the celestial essence perfection: the immutability and incorruptibility of the Heavens had to imply that the nova was nothing else than a meteor located in the sublunar world. To support this conviction, Lorenzini mentioned Aristotle, according to whom the Heavens would stop moving if a new star was added in it; he then introduced a series of reflections about the fact that, as the Heavens was only made of a quintessence, the contrary elements necessary for corruption and generation could not be produced in it, and he concluded with the rhetoric question: in what way could the Heavens corrupt the Heavens to generate the Heavens? After this question, he proposed a long digression about parallax and questions, confused if not even wrong, about geometric-astronomical theorems, and he then presented ideas from the scholastic tradition about lunar spots and the Via Lattea, until a further discussion on the position of the nova. There were also a couple of chapters on the so called "judicial astrology", where Lorenzini discussed the influence of the nova on seasons and harvests, on public health and on physical and moral conditions of humanity.

An answer to Lorenzini arrived very quickly. Six weeks after the publication of the Discorso intorno alla nuova stella, a short booklet was published in Padua with the title Dialogo de Cecco di Ronchitti da Bruzene in perpuosito della Stella Nuova. 
The marginal notes of this booklet contained precise references to Lorenzini's text (Opere, vol. II, pp. 310-34). Written in Paduan dialect, the Dialogo has two main characters, Natale and Matteo: the first one gives an account of the ideas of a Paduan "letterato" (Lorenzini) and the other one ribs these ideas by using Galilean inspired arguments presented in a simple way and with examples taken from everyday life. It is nowadays ascertained that the text was written jointly by Galileo and Girolamo Spinelli, a young Benedictine monk of Galileo's circle. This circle included intellectuals and churchmen like the canon Antonio Querengo, to whom the Dialogo is dedicated - all interested not only in the new developments of science but also in the Paduan dialect and his great mentor, Ruzzante (alias Angelo Beolco). And not only the choice of the Paduan dialect is consistent with Beolco's ideas, but also the choice of the rough characters, who show how the wisdom snaturale can prevail on the book based culture.

The Dialogo, characterised by an irony particularly manifest in the original dialectal version, starts with a conversation on the hypothetical correlation between the drought of the countryside and the appearance of the new star. But if it is really a star, says Matteo, "as it is so far away", it will be difficult to prove that it is the cause of the drought. Natale observes that a Paduan "letterato" supports in a "librazuolo" that the nova is located in the sublunar region. Matteo then asks whether the author of the booklet is an expert of measures and, as he is told that the author "l'é Filuorico" ("he is a philosopher"), he reacts with indignation wondering "what has his philosophy to do with measuring?": the work of mathematicians is intended to carry out measures and they have to be asked about the position of the star. All right, answers Natale, the "letterato" also says that mathematicians carry out measures but they do not understand anything, because they have concluded from their measures that the star is far away and this implies an unacceptable generation and corruption of the Heavens. But this should not matter to mathematicians, answers Matteo upset, because they concern themselves with measuring and not with the essence of things or the substance of what they measure: "even if the star was made of polenta, they could nevertheless observe it". The readers of the Dialogo are thus warned: the controversy on the Stella does not concern the simple field of astronomical observation but it involves the core of philosophical tradition consolidated beliefs. And these beliefs are to be criticised and ribbed in the following pages of the booklet.

Here is the argumentation proposed. Of course, Matteo argues, it is not possible for the moment to prove that the new star is really a star like all the others, but at the same time one can propose a series of conjectures. For instance, as it is not possible that "all the stars in the Heavens could be seen" (a recall to Giordano Bruno's idea), some of them could have merged to give birth to a new visible star, or the nova could have been formed in the air and it could then have raised in the Heavens. As a matter of fact, though this star seems peculiar because of its sudden appearance, which suggests a forthcoming disappearance, who could support that the stars are not, like the Earth, slowly changing, with apparently unperceivable changes? All such arguments are based on the unity of the physics of the Universe, without any distinction between Earth and Heavens. Natale tries to answer to these reflections mentioning once more the "librazuolo", which says that according to Aristotle, the Heavens could not move any longer if a star was added. But in fact, as Matteo points out, this would not be such a big problem, because there are many people "ed anco di buoni" ("and good ones") who believe that the Heavens does not move at all. This evident reference to Copernicans is explicitly written down in a marginal note in the Paduan edition of the Dialogo.

This was more than enough to drive Galileo to publish the Dialogo under a pseudonym. Such a practice was common at that time, but here the issues were particularly delicate 
and they had already started shaking the consolidated powers within and outside the University.

\section{The Copernican system at work}

The content of the Dialogo de Cecco di Ronchitti and the studies on local motions enable Galileo to seize all the opportunities offered by the new instrument, the telescope. The trust in the observation without prejudices and the abandoning of the AristotelianPtolemaic system are the base of his fundamental discoveries. At the same time, his growing trust in the Copernican system enables him to obtain in a natural way some of the consequences of these observations. In particular, as we can read at the end of the Sidereus Nuncius, the discovery of Jupiter's moons is a demonstration of the inadequacy of those who, though accepting at first the Copernican system, become anti Copernican because they do not accept the idea that the Moon revolves around the Earth while both revolve around the Sun in one year. As a matter of fact, we now see that four moons are revolving around Jupiter, and all these celestial bodies together revolve around the Sun in twelve years. We still do not know how this can happen, but it happens, Galielo says (Opere, vol. III, pp. 51-96, p. 95). Fourteen years later, in the letter to Francesco Ingoli of 1624 (Opere, vol. VI, pp. 509-561), with his famous metaphor of the ship (Opere, vol. VI, pp. 547-9), Galileo will provide "physics arguments" (Opere, vol. VI, p. 534) to support the impossibility to prove another of the paradoxes against the Copernican system: if the Earth moves, how can a stone fall perpendicularly to the Earth's surface? Staying on the Earth we cannot decide if the Earth (ship) is motionless or in motion. The physics of local motions can help in understanding questions related to celestial motions. A step forward in the construction of a physics for the Copernican system.

But let's go back to astronomical questions. In the "Postscriptum" of the tables on the Costitutiones of the Medicee added to the Istoria e dimostrazioni intorno alle macchie solari (Opere, vol. V, pp. 247-9, p. 248), Galileo concludes that, in order to explain the observed variations of the length of the eclipses of Jupiter's moons, it is necessary to take into account the fact that the shadow cone of the planet also depends on the annual revolution motion of the Earth [besides the dependence on the "diverse latitudini di Giove" ("different latitudes of Jupiter") and "dall'essere il pianeta che si eclissa de i più vicini o de' più lontani da esso Giove" ("on the fact that the planet that is eclipsed may be one of the closest or most distant from Jupiter")]. Once again the idea of a proof of the Copernican system. The same idea that will bring Galileo to hypothesise, in the same year, that the changing form of Saturn (sometimes with two satellites very close to the two opposite sides of the planet, sometimes alone) could depend on the relative position of the planet with regard to its source of illumination (the Sun) and to the observer (the Earth in its revolution motion) $\dagger$.

$\dagger$ Galileo's hypothesis emerges from a letter written by Agliuchi to Galileo on $13^{\text {th }}$ July 1613 in answer to a letter of Galileo now lost (Opere, vol. XI, pp. 532-5, p. 532). 
The adherence to observed and experimental facts and the research of their explanation within the most advanced scientific knowledge make Galileo a modern scientist. A modernity that we can see also in his contrariety to use Pythagoric or Platonic arguments so current at that time (much diffused, only to mention another great scientist of that time, in Kepler's work). To those who tried to explain, with a-priori arguments, why the moons around Jupiter were right four and, on the basis of these arguments, proposed the existence of other moons around Jupiter or around other planets $\dagger$, Galileo answers indirectly in the letter to Dini written on $21^{\text {th }}$ may 1611 (Opere, vol XI, pp. 105-16, p. 115), reaffirming his adherence to facts: I have observed four (moons) around Jupiter and two moons around Saturn, "non posso negare né affermare cosa alcuna" ("I cannot deny or affirm anything") about whether others exist.

With good cause, many of his contemporaries greeted Galileo as a new Columbus or a new Amerigo Vespucci. $\ddagger$ A similar acknowledgement was to be addressed in 1904, about three hundred years after the discovery of Jupiter's moons, to J. J. Thomson, the scientist who discovered the electron, the first elementary particle (Langevin, The History of Modern Physics).

\section{References}

Opere di Galileo Galilei, Edizione Nazionale a cura di Antonio Favaro (referred to simply Opere in the text)

Langevin, P., "The Relations of Physics of Electrons to other Branches of Science", in K. R. Sopka (ed.), Physics for a new Century, Papers Presented at the 1904 St. Louis Congress, The History of Modern Physics 1986, vol. 5, American Institute of Physics, pp. 195-230, p. 195

$\dagger$ See for instance the letter of Altobelli to Galileo on $17^{\text {th }}$ April 1610 (Opere, vol. X, pp. $317-8$, p. 317), and the Dissertatio of Kepler (Opere, vol III, pp. 100-25).

$\ddagger$ Galileo is compared to Columbus by Orazio dal Monte (letter to Galileo on $16^{\text {th }}$ June 1610, Opere, vol. X, pp. 371-2, p. 372) and by Kepler in his Dissertatio (Opere, vol. III, p. 119), and to Amerigo Vespucci by Ottavio Pisani (two letters to Galileo, the first on $15^{\text {th }}$ September 1613, Opere, vol. XI, p. 564-5, p. 564, and the second on $18^{\text {th }}$ December 1613 , Opere, vol. XI, p. 608-9, p. 608). 